\title{
Surto de criptosporidiose em bezerros no Sul do Rio Grande do Sul ${ }^{1}$
}

\author{
Sergio F. Vargas Jr², Clairton Marcolongo-Pereira ${ }^{3 *}$, Maria de Lourdes Adrien³ ${ }^{3}$ Letícia Fiss ${ }^{2}$, \\ Kayane R. Molarinho ${ }^{4}$, Mauro Pereira Soares ${ }^{3}$, Ana Lucia Schild ${ }^{3}$ e Eliza Simone V. Sallis ${ }^{3 * *}$
}

\begin{abstract}
Vargas Jr S.F., Marcolongo-Pereira C., Adrien M.L., Fiss L., Molarinho K.R., Soares M.P., Schild A.L. \& Sallis E.S.V. 2014. [Outbreak of cryptosporidiosis in calves in Southern Brazil.] Surto de criptosporidiose em bezerros no Sul do Rio Grande do Sul. Pesquisa Veterinária Brasileira 34(8):749-752. Laboratório Regional de Diagnóstico, Faculdade de Veterinária, Universidade Federal de Pelotas, Campus Universitário s/n, Pelotas, RS 96010-900, Brazil. E-mail: esvsallis@yahoo.com.br

This paper describes the epidemiology, clinical signs and pathology of an outbreak of cryptosporidiosis in calves in Southern Brazil. Thirty-five out of 400 calves with 30-45 days of age were affected and 16 died. The calves were born weak and just after birth they had yellow diarrhea, weight loss, dehydration, depression, and death between 10 and 15 days after onset of clinical signs. Congestion of the bowel and mesenteric blood vessels were observed at necropsy. Intestinal distension by gas and dilation of lymphatic vessels were also observed. Microscopically, the intestine showed flattening of the villi with necrosis and atrophy. Adhered to the surface of the villus epithelial cells there were round basophilic structures of 2- to 5- $\mu \mathrm{m}$-diameter compatible with Cryptosporidium spp. Electron microscopy revealed the presence of different stages of the agent adhered to the microvilli of enterocytes. We alert the importance of cryptosporidiosis as a primary agent of diarrhea in calves. Preventive measures to reduce economic losses, environmental contamination, and also decrease of risk for public health are necessary.
\end{abstract}

INDEX TERMS: Cryptosporidiosis, Cryptosporidium spp., calves, diarrhea.

RESUMO.- Descrevem-se os aspectos epidemiológicos, sinais clínicos e a patologia de um surto de criptosporidiose em bezerros na região Sul do Rio Grande do Sul. De um lote de 400 bezerros de 30-45 dias de idade, 35 adoeceram e 16 morreram. Os bezerros nasciam fracos e logo após o nascimento apresentavam diarreia amarela, emagrecimento progressivo, desidratação, depressão e morte entre 10 e 15 dias após o início dos sinais clínicos. Na necropsia havia congestão dos vasos sanguíneos intestinais e mesentéricos. Havia distensão intestinal por gás e dilatação de vasos linfáticos. Microscopicamente havia achatamento das vilosidades in-

\footnotetext{
${ }^{1}$ Recebido em 21 de maio de 2014.

Aceito para publicação em 8 de julho de 2014.

${ }^{2}$ Programa de Pós-Graduação em Veterinária, Faculdade de Veterinária (FV), Universidade Federal de Pelotas (UFPel), Campus Universitário s/n, Pelotas, RS 96010-900, Brasil.

${ }^{3}$ Laboratório Regional de Diagnóstico, FV-UFPel, Campus Universitário s/n, Pelotas, RS. *Bolsista PDJ, CNPq (proc. 150246/2014-5). **Autor para correspondência: esvsallis@yahoo.com.br

${ }^{4}$ Graduanda em Veterinária, FV-UFPel, Pelotas, RS.
}

testinais, com necrose e atrofia. Aderidas à superfície das células epiteliais das vilosidades, havia estruturas puntiformes basofílicas de 2-5 $\mu \mathrm{m}$ de diâmetro compatíveis com Cryptosporidium spp. A microscopia eletrônica revelou a presença de diferentes estágios do agente aderidos às microvilosidades de enterócitos. Alerta-se para a importância da criptosporidiose como agente primário de diarreia em bezerros. São necessárias medidas preventivas no que se refere ao manejo para diminuir as perdas econômicas e a contaminação ambiental, e, ainda, diminuir o risco para a saúde pública.

TERMOS DE INDEXAÇÃO: Criptosporidiose, Cryptosporidium spp., bezerros, diarreia.

\section{INTRODUÇÃO}

Criptosporidiose é uma enfermidade de ocorrência mundial causada por protozoários do gênero Cryptosporidium, que infectam uma ampla gama de hospedeiros (mamíferos, aves, répteis, anfíbios e peixes), inclusive o homem (Rieux et al. 2013). Em bovinos tem sido mencionado que Cryptosporidium parvum, C. andersoni, C. bovis e Cryptosporidium 
genótipo deer-like são as espécies mais prevalentes (Feitosa et al. 2004, Cardoso et al. 2008).

0 papel do C. parvum como causa de diarreia em bovinos é controverso, uma vez que pode ser encontrado em animais sadios. Por outro lado, este protozoário é considerado importante como causa de diarreia em neonatos infectados naturalmente (Radostits et al. 2007). Mais frequentemente age como oportunista em conjunto com outros enteropatógenos, levando a dano intestinal e diarreia (Radostits et al. 2007). Alguns autores descrevem que este protozoário é a segunda causa mais importante de diarreia em bezerros (Moore \& Zeman 1991, De Graff et al. 1999, Blanchard 2012). Os animais adultos são considerados fontes de infecção para o ambiente e para o resto do rebanho, normalmente sendo portadores assintomáticos (Muniz Neta et al. 2010).

Criptosporidiose pode causar sérios prejuízos econômicos, como retardo no crescimento, mortalidade e gastos com medicamentos (Olson et al. 2004, Santín et al. 2008). No Brasil tem sido relatada a presença de oocistos de Cryptosporidium spp. nas fezes de bovinos nos Estados de São Paulo e Rio de Janeiro (Souza \& Lopes 1995, Ederli et al. 2004, Feitosa et al. 2004, Almeida et al. 2008, Cardoso et al. 2008). Surtos de criptosporidiose foram relatados no Canadá (Sanford \& Josephson 1982, Wright et al. 1995) e nos Estados Unidos sendo que neste último havia associação com salmonelose (Cesaro et al. 2014).

O objetivo deste estudo foi descrever os aspectos epidemiológicos, sinais clínicos e a patologia de um surto de criptosporidiose em bezerros na região Sul do Rio Grande do Sul.

\section{MATERIAL E MÉTODOS}

Foi recebido no Laboratório Regional de Diagnóstico (LRD) da Faculdade de Veterinária da Universidade Federal de Pelotas (LRD/ UFPel), um bezerro proveniente de uma propriedade localizada no município de Cristal ( $30^{\circ} 59^{\prime} 59^{\prime \prime}$ S, 52 $2^{\circ} 02^{\prime}$ 54” W), Rio Grande do Sul, apresentando debilidade e diarreia amarela. Na propriedade havia histórico de mortalidade em bezerros com diarreia e emagrecimento progressivo desde o ano anterior. Os dados epidemiológicos e os sinais clínicos foram obtidos com o médico veterinário encarregado da propriedade. 0 bezerro foi eutanasiado in extremis e necropsiado. Fragmentos de todos os órgãos, incluindo o sistema nervoso central foram fixados em formalina $10 \%$, processados rotineiramente e corados com hematoxilina e eosina (HE). Foram coletadas fezes para pesquisa de enterobactérias e nematódeos gastrintestinais. Fragmentos de intestino foram fixados em solução de glutaraldeído $2 \%$ e paraformaldeído $2 \%$ em solução tamponada de cacodilato de sódio, desidratados em etanol e embebidos em resina Epon 812. Cortes semifinos foram corados com azul de metileno e cortes ultrafinos foram feitos das áreas selecionadas. 0 material foi contrastado com acetato de uranila e citrato de chumbo e observado a $80 \mathrm{kV}$ em microscópio de transmissão Zeiss EM 109 - West Germany.

\section{RESULTADOS}

O surto ocorreu em novembro de 2012 em um lote de 400 bezerros, dos quais $35(8,75 \%)$ adoeceram e $16(4 \%)$ morreram. Os bovinos eram fêmeas de aproximadamente 3045 dias de idade, sem raça definida.
Os bezerros nasciam fracos e logo após o nascimento apresentavam diarreia amarela (Fig.1), emagrecimento progressivo, desidratação, depressão e morte entre 10 e 15 dias após o início dos sinais clínicos. Os bovinos eram mantidos em campo nativo e, segundo o veterinário, no ano 2011 cerca de 70 bezerros morreram com sinais clínicos semelhantes e várias tentativas de diagnóstico em exames parasitológicos e culturas fecais foram realizados sem sucesso. Tanto no surto de 2011 como em 2012 os bezerros com sinais clínicos foram tratados com dipirona e oxitetraciclina, também, sem que houvesse resposta positiva dos animais. As vacas mães dos bezerros eram vacinadas para diarreias neonatais e contra as doenças reprodutivas [rinotraqueite infecciosa bovina (IBR)/diarreia viral bovina (DVB) e leptospirose].

Na necropsia do bezerro encaminhado ao LRD/UFPel, macroscopicamente havia congestão dos vasos sanguíneos intestinais e mesentéricos. 0 intestino delgado apresentava distensão, com presença de gás e com conteúdo esverdeado. 0 intestino grosso estava, também, distendido, os linfonodos mesentéricos estavam aumentados de tamanho e os vasos linfáticos dilatados (Fig.2).

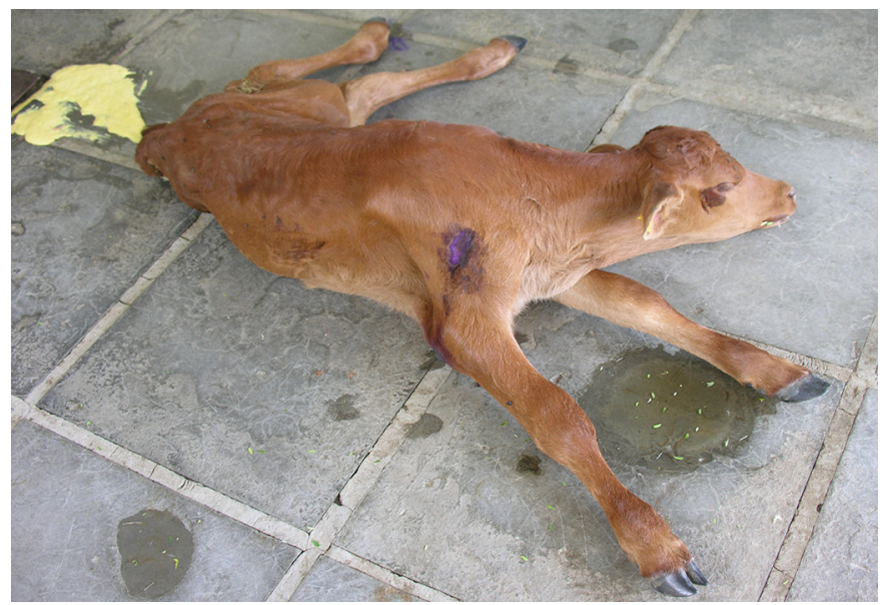

Fig.1. Bezerro com criptosporidiose apresentando fraqueza e diarreia amarela.

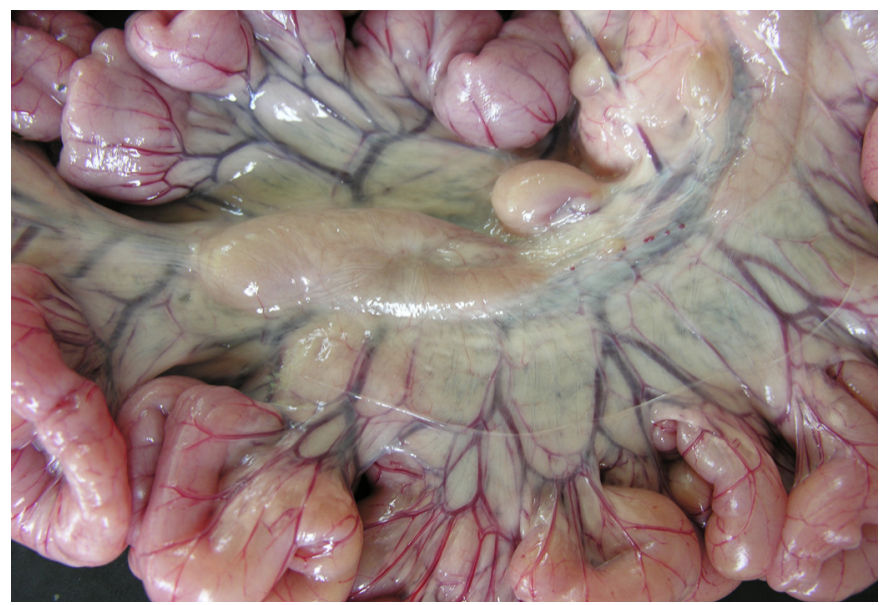

Fig.2. Intestino delgado de bezerro com criptosporidiose distendido por gás. Observa-se congestão dos vasos sanguíneos e aumento dos linfonodos. Os vasos linfáticos estão dilatados. 
As lesões histológicas caracterizaram-se por necrose e achatamento das vilosidades intestinais, resultando na atrofia das mesmas. Havia congestão dos vasos sanguíneos da lâmina própria com infiltrado inflamatório de linfócitos, plasmócitos e raros eosinófilos. Aderidas à superfície das células epiteliais das vilosidades, havia estruturas puntiformes basofílicas de $2-5 \mu \mathrm{m}$ de diâmetro compatíveis com Cryptosporidium spp. (Fig.3). Ultraestruturalmente foram observadas estruturas arredondadas medindo 1,5 a 1,75 $\mu \mathrm{m}$ de diâmetro, as quais se encontravam aderidas à microvilosidades dos enterócitos e correspondiam a trofozoítos de Cryptosporidium spp. (Fig.4). Havia, também, hiperplasia dos folículos linfoides do intestino. Na cultura bacteriológica das fezes não houve crescimento bacteriano e o exame parasitológico foi negativo.

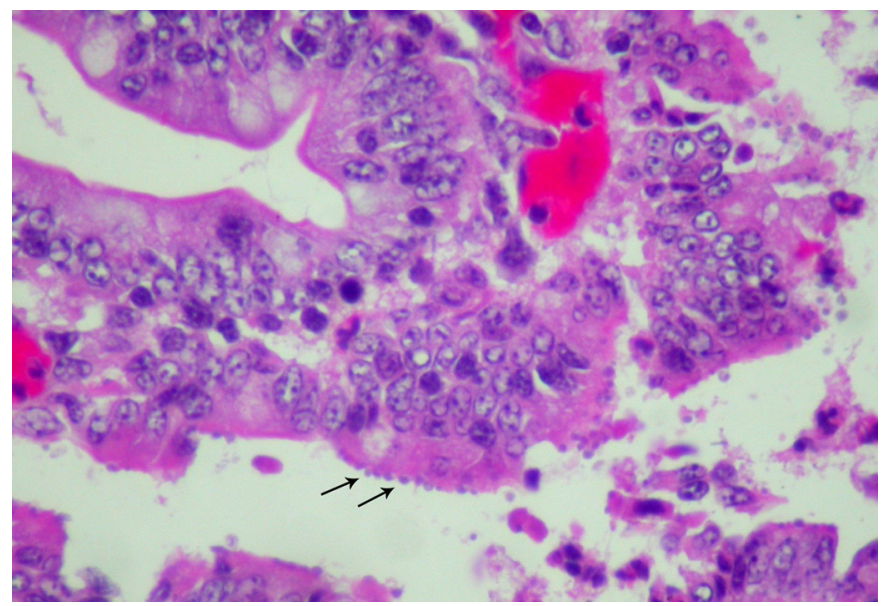

Fig.3. Formas parasitárias de Cryptosporidium spp. aderidas à superfície das vilosidades (setas). HE, obj.40x.

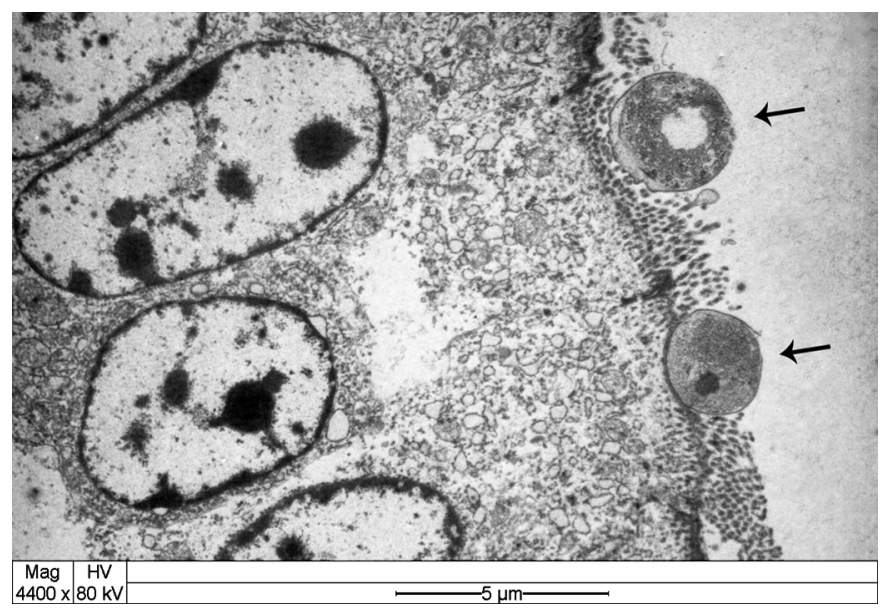

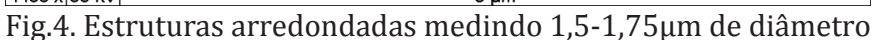
que correspondem a trofozoítos de Cryptosporidium spp. aderidos às microvilosidades de enterócitos (setas).

\section{DISCUSSÃO E CONCLUSÕES}

O diagnóstico de criptosporidiose foi realizado com base nos dados epidemiológicos, sinais clínicos, lesões macroscópicas e histológicas e presença do agente nas células epiteliais das vilosidades intestinais.
Tem sido descrito que apesar de Cryptosporidium ser considerado um patógeno oportunista pode ser causa primária de diarreia em bezerros (Panciera et al. 1971, Sanford \& Josephson 1982, Moore \& Zeman 1991, De Graff et al. 1999). A mortalidade ocorre em geral quando o Cryptosporidium está associado a outros patógenos entéricos (De Graff et al. 1999). No entanto, em um estudo sobre a criptosporidiose no Canadá outros agentes patogênicos que causam diarreia em bezerros foram identificados em menos de 50\% dos casos de diarreia (Sanford \& Josephson 1982, Moore \& Zeman 1991).

A doença tem sido descrita em outros países como Estados Unidos e Canadá ocorrendo nos meses de inverno quando os bezerros são confinados em espaços reduzidos favorecendo a contaminação pelos oocistos (Anderson \& Bulgin 1981, Sanford \& Josephson 1982). No presente relato o surto ocorreu na primavera, época da parição na região Sul do Brasil, que é quando as vacas eliminam o maior número de oocistos nas fezes. Animais adultos são considerados fontes de infecção para o ambiente e para o resto do rebanho, normalmente sendo portadores assintomáticos do parasita (Muniz Neta et al. 2010). Apesar da criação extensiva neste caso, os animais nasciam em uma mesma área na qual se contaminavam. Tem sido demonstrado que bezerros afetados e vacas infectadas podem eliminar grande quantidade de oocistos nas fezes, razão pela qual o local de parição estava aparentemente altamente contaminado, favorecendo a infecção dos neonatos. A morte de cerca de 70 bezerros no ano anterior com os mesmos sinais clínicos reforça esta hipótese. Surtos anuais de criptosporidiose podem ocorrer na mesma propriedade, devido à persistência dos oocistos infectantes no ambiente (Angus 1987, Feitosa et al. 2008).

A doença ocorreu de forma aguda e grave, com mortalidade, aparentemente sem associação de outros agentes bacterianos, já que não houve crescimento nas culturas realizadas. Os patógenos virais (coronavirus e rotavirus) poderiam estar associados ao Cryptosporidium como agentes etiológicos da diarreia, no entanto o isolamento viral não foi realizado. Por outro lado, estes virus afetam bezerros mais jovens geralmente até 14 dias de idade (Radostits 2007). Outro fato que reforça a possibilidade de Cryptosporidium spp. ter sido a causa primária foi que a mudança no manejo da propriedade com eliminação da área de parição controlou a mortalidade e nos anos subsequentes não ocorreram casos de diarreia entre os bovinos nascidos. Em um estudo de 277 casos de criptosporidiose nos Estados Unidos foi demonstrado que é possível o desenvolvimento de doença aguda grave em bezerros pela infecção por Cryptosporidium spp. sem associação de outros patógenos (Moore \& Zeman 1991).

O tratamento utilizado na propriedade sem sucesso reforça a infecção por Cryptosporidium spp. em dois anos consecutivos, já que é mencionado que este protozoário é resistente a antibióticos e antiparasitários comuns e permanece no solo por vários meses, principalmente no verão, sendo também altamente resistente a desinfetantes o que dificulta a descontaminação ambiental (Blanchard 2012).

Outro fato que deve ser mencionado é que no ano 2011 o diagnóstico da doença não foi realizado após inúmeros 
exames fecais dos bovinos afetados. Tem sido mencionado que a realização de exame parasitológico de fezes tem baixa eficiência para realizar o diagnóstico de criptosporidiose além de não ser possível determinar a gravidade da doença somente por este exame (Moore \& Zeman 1991). Esta poderia ser a razão pela qual o diagnóstico da doença não foi confirmado no ano anterior. A presença de oocistos de Cryptosporidium spp. em bezerros tem sido relatada em diferentes Estados brasileiros, no entanto a presença do oocisto nas fezes não implica em doença clínica (Radostits et al. 2007).

Alerta-se para a importância da criptosporidiose não só como um agente oportunista, mas também como agente primário de diarreia em bezerros. Medidas preventivas devem ser tomadas, relacionadas ao manejo de vacas na época da parição evitando a aglomeração de animais e a contaminação ambiental para diminuir as perdas econômicas, além de evitar os riscos para a saúde pública advindos da infecção.

\section{REFERÊNCIAS}

Almeida A.J., Oliveira F.C.R. \& Teixeira C.S. 2008. Risco relativo da infecção por parasitos do gênero Cryptosporidium em bezerros bovinos no norte do estado do Rio de Janeiro, Brasil. Revta Bras. Parasitol. Vet. 17(Supl.1):243-248.

Anderson B.C. \& Bulgin M.S. 1981. Enteritis caused by Cryptosporidium in calves. Vet. Med. Small Anim. Clin. 76(6):865-868.

Angus K.W. 1987. Cryptosporidiosis in domestic animals and humans. In Practice 9:47-49.

Blanchard P.C. 2012. Diagnostics of dairy and beef cattle diarrhea. Vet. Clin. Food Anim. 28:443-464.

Cardoso J.M.S., Silveira F.L., Araújo A.J.U.S., Carvalho J.C.C. \& Kanamura H.Y. 2008. Ocorrência de Cryptosporidium spp. em um rebanho bovino leiteiro no município de Caçapava, estado de São Paulo, Brasil. Revta Bras. Parasitol. Vet. 17(Supl.1):239-242.

Cesaro M.P., Pierezan F., Heins B.D. \& Brown C.C. 2014. Pathology in practice. J. Am. Vet. Med. Assoc. 244(1):53-55.

De Graff D.C., Vanopdenbosch E., Ortega-Mora L.M., Abbassi H. \& Peeters J.E. 1999. A review of the importance of cryptosporidiosis in farm animals. Int. J. Parasitol. 29:1269-1287.
Ederli B.B., Carvalho C.B. \& Sales L.G. 2004. Ocorrência da infecção por Cryptosporidium em bezerros na microrregião de Campos dos Goytacazes no Norte do Estado do Rio de Janeiro, Brasil. Revta Bras. Parasitol. Vet. 13:45-48.

Feitosa T.F., Shimamura G.M., Roberto T., Mendes L.C.N., Peiró J.R., Féres F.C., Bovino F., Perri S.V.P. \& Meireles M.V. 2008. Importância de Cryptosporidium spp. como causa de diarreia em bezerros. Pesq. Vet. Bras. 28(10):452-456.

Feitosa L.L.F., Shimamura G.M., Roberto T., Meireles M.V., Nunes C.M., Ciarlini P.C. \& Borges A.S. 2004. Prevalência de criptosporidiose em bezerros na região de Araçatuba, estado de São Paulo, Brasil. Ciência Rural 34(1):189-193.

Moore D.A. \& Zeman D.H. 1991. Cryptosporidiosis in neonatal calves: 277 cases (1986-1987). J. Am. Vet. Med. Assoc. 198(11):1969-1971.

Muniz Neta E.S., Sampaio D.C., Galvão G.S. \& Munhoz A.D. 2010. Comparação das técnicas de Ziehl-Neelsen modificada e contraste de fase na detecção de oocistos do gênero Cryptosporidium Tyzzer, 1907 (Apicomplexa: Cryptosporidiidae) em bovinos assintomáticos. Revta Bras. Med. Vet. 32(4):201-204.

Olson M.E., O'handley R.M., Ralston B.J., McAllister T.A. \& Thompsom R.C.A. 2004. Update on Cryptosporidium and Giardia infections in cattle. Trends Parasitol. 20:185-191.

Panciera R.J., Thomassen R.W. \& Garner F.M. 1971. Cryptosporidial infection in a calf. Vet. Pathol. 8:479-484.

Radostits O.M., Gay C.C., Hinchcliff K.W. \& Constable P.E. 2007. Veterinary Medicine: a textbook of the diseases of cattle, horses, sheep, pigs and goats. $10^{\text {th }}$ ed. W.B. Saunders, London. 2065p.

Rieux A., Chartier C., Pors I., Delafosse A. \& Paraud C. 2013. Molecular characterization of Cryptosporidium isolates from high-excreting young dairy calves in dairy cattle herds in Western France. Vet. Parasitol. 192(1/3):268-272.

Sanford S.E. \& Josephson G.K.A. 1982. Bovine cryptosporidiosis: clinical and pathological findings in forty-two scouring neonatal calves. Can. Vet. J. 23:343-347.

Santín M., Trout J.M. \& Fayer R. 2008. A longitudinal study of cryptosporidiosis in dairy cattle from birth to 2 years of age. Vet. Parasitol. 155(1/2):15-23.

Souza J.C.P. \& Lopes C.W.G. 1995. Criptosporidiose em bezerros de rebanhos da bacia leiteira Sul-Fluminense, Estado do Rio de Janeiro. Revta Bras. Parasitol. Vet. 4:33-36.

Wright A.K., Giger R., Arnold T.M. \& Janzen E.D. 1995. An episode of diarrhea in calves of a well-managed dairy herd. Can. Vet. J. 36:36-38. 